\title{
Dynamics of water in the partially crystallized gelatin water mixture
}

\section{部分的に永結したゼラチン水溶液の水のダイナミクス}

\author{
Kaito SASAKI, Masahiko MIYARA, Rio KITA, Naoki SHINYASHIKI and Shin YAGIHARA \\ Department of Physics, Tokai University, 4-1-1 Kitakaname, Hiratsuka, Kanagawa, 259-1292, Japan \\ TEL: +81-463-58-1211 FAX: +81-463-59-2207 e-mail: naoki-ko@keyaki.cc.u-tokai.ac.jp \\ (Received 31 January, $2013 \quad$ Accepted 20 June, 2013)
}

\begin{abstract}
Dielectric relaxation process of water was investigated for $30 \mathrm{wt} \%$ gelatin-water mixture at frequencies between $1 \mathrm{MHz}$ and $50 \mathrm{GHz}$ in subzero temperatures down to $-50{ }^{\circ} \mathrm{C}$. Below the melting temperature $T_{\mathrm{m}}$, part of water crystallized and another part of water, uncrystallized water (UCW), remained in a liquid state with gelatin in an uncrystallized phase. At $T_{\mathrm{m}}$, the relaxation strength, relaxation time, and relaxation time distribution change adruptly, and their subsequent changes with decreasing temperature are larger than those above $T_{\mathrm{m}}$. These large temperature dependences below $T_{\mathrm{m}}$ can explained by the increase in gelatin concentration in the uncrystallized phase $C_{\mathrm{g}, \mathrm{UCP}}$ with decreasing temperature.
\end{abstract}

Keywords : Gelatin, Water, Partial crystalization, Dynamics, Dielectric relaxation

\section{INTRODUCTION}

これまでに、合成高分子水溶液やタンパク質水溶液に ついて断熱熱量計や示差走査型熱量測定(Differential Scanning Carorimetry: DSC)などの熱分析により、水の凍 結及び融解についての研究が盛んに行われてきた。1様々 な高分子溶液で観測される水の融解によるエンタルピー 変化 $\Delta H$ は溶液中の寸べての水が凍結した場合と比較し て小さい值を持つ。これは融解温度 $T_{\mathrm{m}}$ 以下でも凍るこ となく、液体状態を維持した不凍水と呼ばれる水が存在 するためであると考えられる。しかし、これらの熱的な 観測手法では不凍水を直接観測することができない。

誘電分光法(Dielectric Relaxation Spectroscopy: DRS)は 幅広い観測時閒空を持ち、分子運動を詳細に議論するこ とができる強力な手法である。広い温度、濃度範囲にお ける様々な合成高分子水溶液の研究 2 や、非水素結合性 液体を溶媒とした合成高分子溶液の研究 3 、部分的に氷 結したウシ血清アルブミンを始めとした球状タンパク質 の研究 4,5 からも不凍溶液の存在が確かめられており、溶 媒の部分的な凍結が系のダイナミクスを支配しているこ とが明らかになっている。

SAS Award was given to this paper presented as Poster Presentation at the 2012 SAS Intelligent Symposium.
これまでに我々はタンパク質の一種であるゼラチンを 用いた水溶液のガラス転移に関寸る研究 6,7 を広帯域の 誘電分光法を用いて行なってきた。本研究ではより高周 波領域を詳しく観測することで、水のダイナミクスを明 らかにするものである。そのために溶質濃度 $30 \mathrm{wt} \%$ の゙ ラチン水溶液を調整し、凍結する温度を含む $-40 \sim 25^{\circ} \mathrm{C}$ の 温度範囲を $1 \mathrm{MHz}-50 \mathrm{GHz}$ の周波数域で誘電分光測定を 行った。さらに-55 25 ${ }^{\circ} \mathrm{C}$ の温度範囲を昇温速度 $5^{\circ} \mathrm{C} / \mathrm{min}$ で示差走查型熱量計による熱分析を行った。

\section{EXPERIMENTAL}

\section{II-A. Methods}

誘電分光測定は 2 つの装置を用い、周波数範囲 1 $\mathrm{MHz} 50 \mathrm{GHz}$ で行った。周波数範囲 $1 \mathrm{MHz} 3 \mathrm{GHz}$ の測 定には Impedance/Material Analyzer (Agilent Technologies、 E4991A)(IMA)を用い、周波数範囲 $100 \mathrm{MHz} 50 \mathrm{GHz}$ の測 定には Network Analyzer (Agilent Technologies、N5230C) (NA)を用いた。循環式恒温槽を用いて NA では温度範囲 $-10 \sim 25^{\circ} \mathrm{C}$ の間で、 $\pm 0.1{ }^{\circ} \mathrm{C}$ の範囲に温度を安定させて測 定を行った。また、IMA での測定には Quatro Cryosystem (Novocontrol)を使用し、測定温度範囲-50 25 ${ }^{\circ} \mathrm{C}$ の間で、 $\pm 0.01{ }^{\circ} \mathrm{C}$ の範囲に温度を安定させた。IMA での測定には 平行平板型電極を用い、NA での測定には接触式の同軸 
開放端電極(Agilent Technologies、85070E)を用いた。

また、示差走査型熱量計(Perkin Elmer、DSC7) (DSC)に より、ゼラチン水溶液の融解に伴う熱の出入りを一 $55 \sim 25{ }^{\circ} \mathrm{C}$ の範囲で測定した。測定前にベンゼン、1, 2 ジ クロロエタンを用い、測定と同じ昇温、降温速度で校正 を行った。測定には、ヘリウム雰囲気下において、アル ミニウムの容器に封入された $10 \mathrm{mg}$ 程度の試料を、 $25^{\circ} \mathrm{C}$ から $-60^{\circ} \mathrm{C} に 5{ }^{\circ} \mathrm{C} / \mathrm{min}$ の泠却速度で泠却し、 $-60{ }^{\circ} \mathrm{C}$ で 10 分間放置した後、 $5{ }^{\circ} \mathrm{C} / \mathrm{min}$ の昇温速度で $25^{\circ} \mathrm{C}$ まで加熱 しながら測定した。

水は過冷却状態になりやすく、結晶化温度は冷却速度 によって大きく変化し、議論が困難である。そのため本 研究では、昇温過程における融解を観測した。

\section{II-B. Sample}

溶質として使用したゼラチンは、PM Biomedicals 製、 豚皮由来のものであり、ブルーム強度 251 bloom、分子量 約 $60,000 \mathrm{~g} / \mathrm{mol}$ である。一般にゼラチンなどの生体高分 子は電解質高分子であるため、その水溶液は溶液中に含 まれるイオンによる直流電気伝導成分 $(\mathrm{dc})$ や電極分極の 寄与により、分子運動に起因する緩和が隠れてしまう。 それらを軽減するためにゼラチンに対して脱イオン処理 を施した。まず、ゲル化させた濃度 $10 \mathrm{wt} \%$ 程度のゼラチ ン水溶液を $5 \mathrm{~mm}$ 角の立方体に裁断し、純水に浸す。こ こで用いた純水は、蒸留後、純水製造器 (Millipore, SimSimpllicity UV)を用い、紫外線による滅菌や活性炭入 イルターによるろ過、イオン交換樹脂による脱イオン処 理などの精製を施したものであり、比抵抗は $18.2 \mathrm{M} \Omega \cdot \mathrm{cm}$ であった。ゼラチンゲル中に含まれるイオンは、純水中 に分散されるため、ゼラチンからイオンを除去すること ができる。脱イオン処理を 5 日間行い、最初の 1 日は数 時間おきに 5 回以上、2 日目以降は 1 日最低 2 回水換え を繰り返した。その後、水分を除去するために凍結乾燥 を行った。溶媒には上記のものと同じ純水を使用し、ゼ ラチン濃度 $C_{\mathrm{g}}$ が $30 \mathrm{wt} \%$ となるようにそれぞれ混合した 後、60 ${ }^{\circ} \mathrm{C}$ に加熱し均一な試料を調製した。

\section{RESULTS}

\section{III-A. DRS}

Figure 1 に DRS 測定により得られた様々な温度での誘 電率 $\left(\varepsilon^{\prime}\right)$ と誘電損失 $(\varepsilon ”)$ の周波数依存性を示す。最も低い 温度、 $-50{ }^{\circ} \mathrm{C}$ では、誘電損失においてブロードなピーク が $10 \mathrm{MHz}$ 付近に見られる。このピークは温度上昇に伴 い高周波側へシフトし、25 ${ }^{\circ} \mathrm{C}$ では $10 \mathrm{GHz}$ 付近にピーク を持つ緩和へと続く。

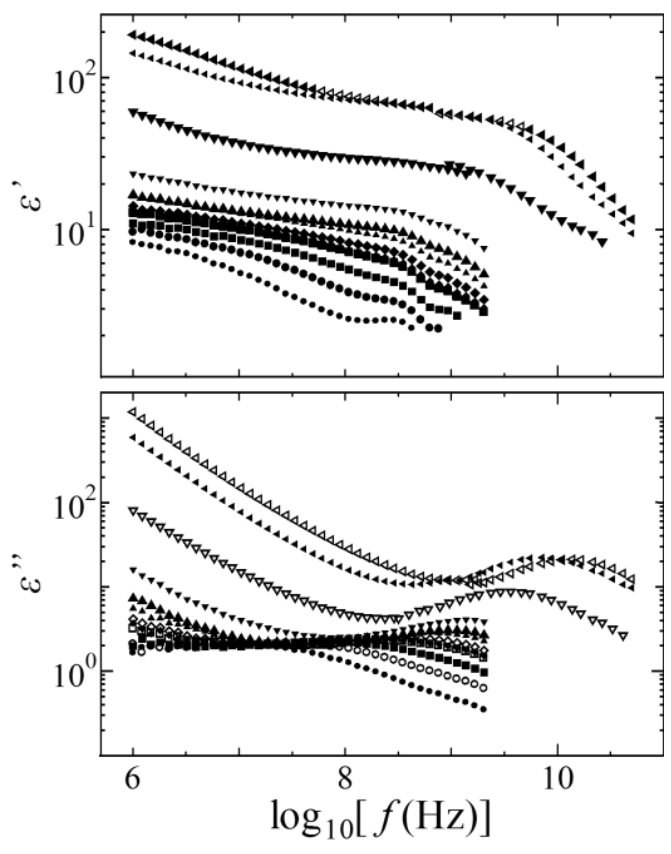

Fig. 1. Real and imaginary parts of the complex permittivity for $30 \mathrm{wt} \%$ gelatin-water mixture at various temperatures: $\mathrm{O},-50^{\circ} \mathrm{C} ; \mathrm{O},-40^{\circ} \mathrm{C}$; $\mathbf{\square}$, $30^{\circ} \mathrm{C} ; \square,-20^{\circ} \mathrm{C} ; \diamond,-17^{\circ} \mathrm{C} ; \diamond,-14^{\circ} \mathrm{C} ; \boldsymbol{\Delta},-11^{\circ} \mathrm{C}$; $\triangle,-8^{\circ} \mathrm{C} ; \nabla,-5^{\circ} \mathrm{C} ; \nabla,-2^{\circ} \mathrm{C} ; \triangleleft, 15^{\circ} \mathrm{C} ; \triangleleft, 25^{\circ} \mathrm{C}$.

測定された複素誘電率からそれぞれの緩和の情報を得 るため、式(1)のように 3 つの Coe-Cole $の$ 式 ${ }^{8}$ と直流電気 伝導成分 $(\mathrm{dc})$ の寄与を重站わせることで複素誘電率の の周波数依存性を再現した。

$$
\varepsilon^{*}=\varepsilon_{\infty}+\sum \Delta \varepsilon /\left(1+(\mathrm{j} \omega \tau)^{\beta}\right)+\sigma / \mathrm{j} \omega \varepsilon_{0}
$$

ここで $\omega$ は角周波数、 $\beta$ は緩和の形を表すパラメータ、 $\Delta \varepsilon$ は緩和強度、 $\tau$ は緩和時間、 $\sigma$ は電気伝導度である。 本研究では測定周波数範囲に明確なピークを確認するこ とができるI緩和にのみ注目する。

Figure 2 に I 緩和の $\tau(\mathrm{a}) 、 \Delta \varepsilon(\mathrm{b})$ の温度依存性を示す。図 から、 $\tau 、 \Delta \varepsilon$ の温度依存性について、 $0^{\circ} \mathrm{C}$ 以上と $-10^{\circ} \mathrm{C}$ 以 下の範囲ではゆるやかな変化が見られる。しかし、0 ${ }^{\circ} \mathrm{C}$ から-10 ${ }^{\circ} \mathrm{C}$ の範囲では劇的な変化が見られる。Figure $2(\mathrm{~b})$ の直線は $0{ }^{\circ} \mathrm{C}$ 以上のプロットから最小二乗法を用いて 引いた。

\section{III-B. DSC}

Figure 3 にDSC による熱測定によって得られた熱流の 温度依存性を示す。溶液中の水の融解によるブロードな 


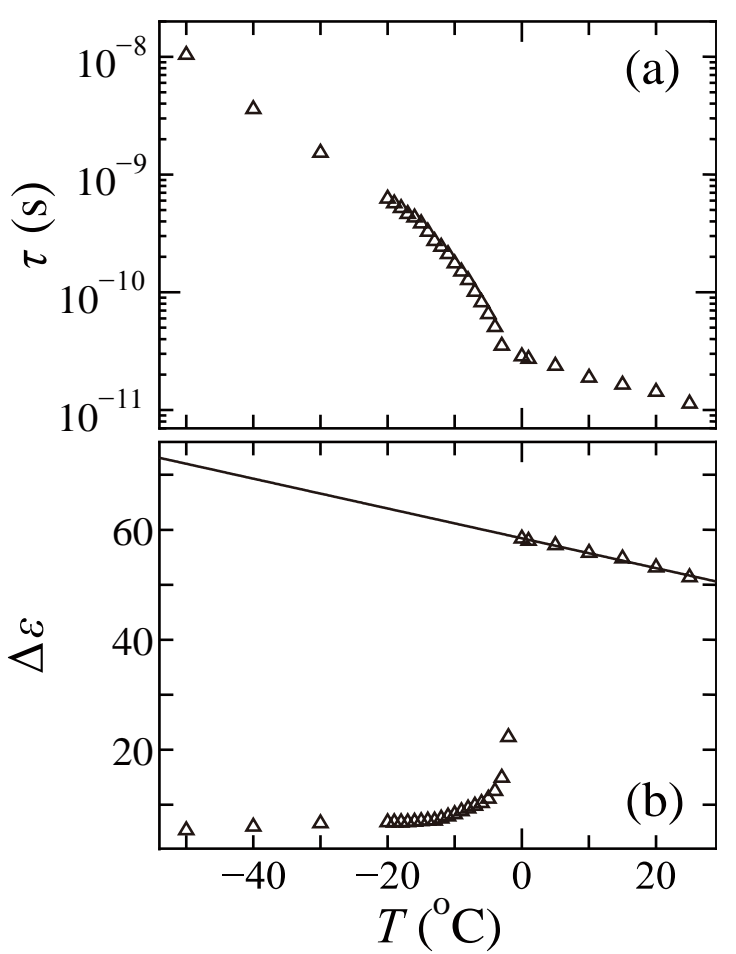

Fig. 2. Temperature dependences of relaxation time (a) and relaxation strength (b) for $30 \mathrm{wt} \%$ gelatinwater mixture. Solid line is given by least-squares method from $\Delta \varepsilon$ above $T_{\mathrm{m}}$.

吸熱ピークが-10 0 ${ }^{\circ} \mathrm{C}$ の間で見られる。このピーク面積 から融解熱 $\Delta H=164 \mathrm{~J} / \mathrm{g}$ を得た。測定された $\Delta H$ から、以 下の式(2)により不凍溶液相の濃度 $C_{\mathrm{g}, \mathrm{UCP}}$ を算出すること ができる。

$$
C_{\mathrm{g}, \mathrm{UCP}}=C_{\mathrm{g}} /(1-(\Delta H / 333))
$$

純水 $1 \mathrm{~g}$ の融解熱 $333 \mathrm{~J} / \mathrm{g}$ を用いてゼラチン水溶液の融解 熱量から凍っていない水の量を算出し、 $C_{\mathrm{g}, \mathrm{UCP}}$ を見積も ると $C_{\mathrm{g}, \mathrm{UCP}[\mathrm{DSC}]}$ は $59 \mathrm{wt} \%$ となった。

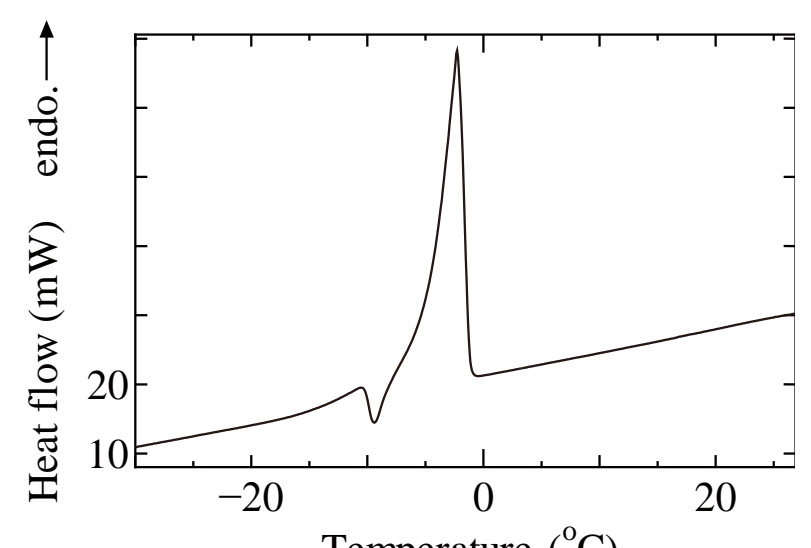

Fig. 3. DSC thermogram for $30 \mathrm{wt} \%$ gelatin-water mixture.

\section{DISCUSSION}

$25^{\circ} \mathrm{C}$ での I 緩和の $\tau$ が純粋な水の緩和時間 9 とよく一 致することから、ゼラチン水溶液で観測された I 緩和は、 低温でも結晶化しない不凍水のダイナミクスに起因する ものであることが分かる。また、一般に緩和強度は温度 の上昇に伴い減少するため、 $-10 \sim 0{ }^{\circ} \mathrm{C}$ で見られる $\Delta \varepsilon$ の 不連続性は氷の融解による不凍水の増加によるものと考 えられる。

融解温度、 $T_{\mathrm{m}}$ 以上での $\Delta \varepsilon$ が Figure $2(\mathrm{~b})$ に示した直線 のように温度の変化に対して一次関数的に変化すると仮 定すれば、以下の式を用いることで $T_{\mathrm{m}}$ 以下での $C_{\mathrm{g}, \mathrm{UCP}}$ を 算出することができる。

$$
C_{\mathrm{g}, \mathrm{UCP}}=C_{\mathrm{g}} /\left(C_{\mathrm{g}}+\left(100-C_{\mathrm{g}}\right) \Delta \varepsilon / \Delta \varepsilon \text { all }\right)
$$

ここで、 $C_{\mathrm{g}}$ は調製したゼラチン濃度、 $\Delta \varepsilon_{\mathrm{all}}$ は $T_{\mathrm{m}}$ 以下にお けるそれぞれの温度で $T_{\mathrm{m}}$ 以上での緩和強度の温度依存 性から推測される、すべての水が凍らなかったと仮定し た場合のI緩和の緩和強度である。Figure 4 に式 3 から 得られた $C_{\mathrm{g}, \mathrm{UCP}}$ と温度の関係を示す。Figure 4 から、十分 低い温度で $C_{\mathrm{g}, \mathrm{UCP}}$ は 80 85 wt\%程度であることがわかる。 温度の上昇にともない、 $-10^{\circ} \mathrm{C}$ 付近から低下し始め、 $0{ }^{\circ} \mathrm{C}$ 以上で $C_{\mathrm{g}}$ と一致する。DSC による熱分析で得られた

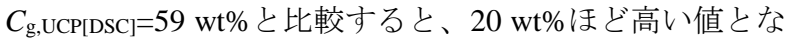
り一致しない。この原因は、2 つの測定法で試料の温度 履歴が全く異なることが考えられる。DRS 測定では各温 度での測定前に最低 20 分は温度の安定化を行うが、DSC での測定は $5^{\circ} \mathrm{C} / \mathrm{min}$ の速度で温度を変化させながら測定 を行う。そのため、DSCでの熱分析では氷の結晶が十分 に成長することができず不凍水量が多くなり、不凍溶液 相のゼラチン濃度が低くなると考えられる。

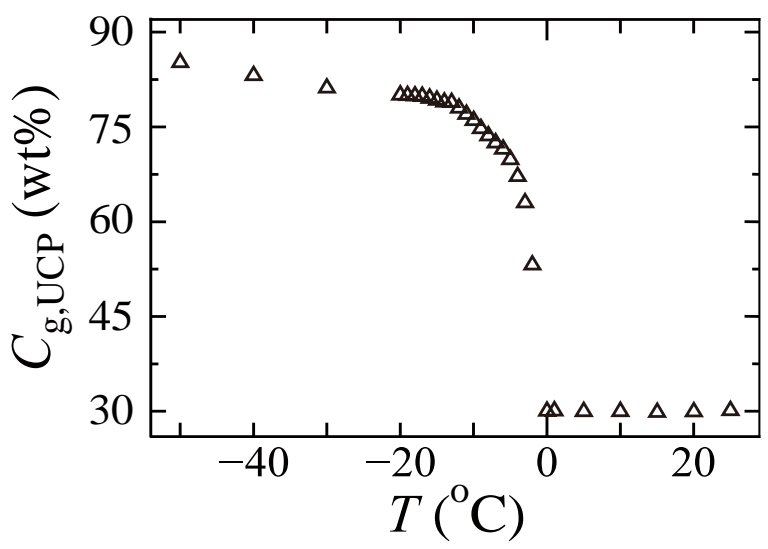

Fig. 4. Temperature dependence of gelatin concentration in the uncrystallized phase $C_{\mathrm{g}, \mathrm{UCP}}$ for 30 wt $\%$ gelatin-water mixture. 
次に $C_{\mathrm{g}, \mathrm{UCP}}$ と $T_{\mathrm{m}}$ 以下での $\tau$ の関係を Figure 5 に示す。 図中の黒塗りのプロットは $0{ }^{\circ} \mathrm{C}$ のデータである。図から、 $\tau$ は溶液中の水の融解による不凍溶液相の濃度低下に伴 い、黒のXで示した $0.2{ }^{\circ} \mathrm{C}$ での純粋な水のプロット ${ }^{9} に$ 近づいていることが分かる。ことから、不凍溶液相の水 の $\tau$ の急激な変化は、 $T$ と $C_{\mathrm{g}, \mathrm{UCP}}$ によって決定されると 考えることができる。これらを部分的に凍結した合成高 分子水溶液中の不凍水のダイナミクス 2 と比較すると非 常によく似ていることがわかった。

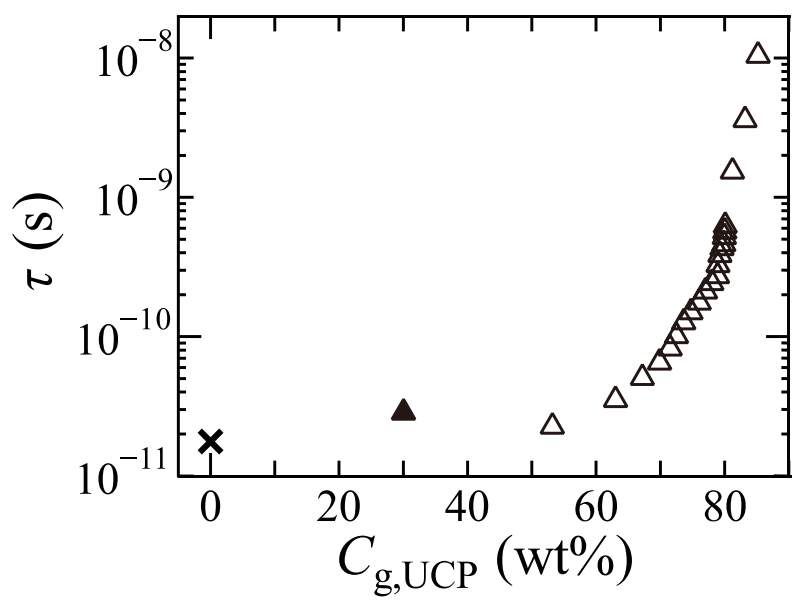

Fig. 5. Relaxation time against the gelatin concentration in the uncrystallized phase $C_{\mathrm{g}, \mathrm{UCP}}$ for the $30 \mathrm{wt} \%$ gelatin-water mixture. The " $\times$ " symbol is the $\tau$ for pure water at $0.2{ }^{\circ} \mathrm{C}$ taken from Ref. 9 and the filled symbol indicate data at above $T_{\mathrm{m}}$.

\section{CONCLUSION}

周波数範囲 $1 \mathrm{MHz} 50 \mathrm{GHz}$ 、温度範囲 $-50 \sim 25^{\circ} \mathrm{C}$ 、濃度 $30 \mathrm{wt} \%$ のゼラチン水溶液の昇温過程による DRS 及び DSC 測定により、水の融解に伴う水のダイナミクスの変 化を観測した。その結果を以下の項目にまとめる。 1 ) $30 \mathrm{wt} \%$ †゙ラン水溶液においても $0{ }^{\circ} \mathrm{C}$ 以下でも凍ら ない水が存在することが DRS 測定で確かめられた。

2 ) 液体状態の水の緩和強度の温度依存性から、-10 ${ }^{\circ} \mathrm{C}$ 以下での不凍溶液相のゼラチン濃度は 80 85 wt \%である ことがわかった。

3 ) $-20 \sim 0{ }^{\circ} \mathrm{C}$ の $\tau$ 急激な変化は、部分的な凍結による 不凍溶液相のゼラチン濃度の増加に支配されることがわ かった。

4) DRS 測定とDSC 測定では、算出された不凍溶液相
のゼラチン濃度が異なった。

現段階では測定結果のばらつきも大きく、また、他の タンパク質水溶液での報告がないため、明確でないこと も多い。しかし、DRS 測定からは誘電緩和パラメータを 通して、ダイナミクスや不凍水量などの情報を得ること ができる。

\section{ACKNOWLEDGEMENTS}

本研究の一部はJSPS科研費22540420、東海大学プロ ジェクト研究「水構造プロジェクト」、科学技術振興機 構研究成果展開事業・先端計測分析技術プログラムの支 援を得て遂行された。関係各位に深謝する。

\section{REFERENCES}

${ }^{1}$ F. Franks, Water, A Comprehensive Treatise, (Plenum Press, New York), Vol. 7, Chapter 3, 1982. ${ }^{2}$ N. Shinyashiki, M. Shimomura, T. Ushiyama, T. Miyagawa and S. Yagihara, J. Phys. Chem. B, 111, 10079 - 10087, (2007).

${ }^{3}$ N. Shinyashiki, M. Asano, M. Shimomura, S. Sudo, R. Kita and S. Yagihara, J. Biomater. Sci. Polym. Ed., 21, 1937 - 1946, (2010).

4 A. Panagopoulou, A. Kyritsis, R. Sabater i Serra, J.L. Gómez Ribelles, N. Shinyashiki and P. Pissis, Biochim. Biophys. Acta, 1814, 1984 - 1996, (2011).

5 N. Shinyashiki, W. Yamamoto, A. Yokoyama, T. Yoshinari, S. Yagihara, R. Kita, K. L. Ngai and S. Capaccioli, J. Phys. Chem. B, 113, 14448 - 14456, (2009).

${ }^{6}$ K. Sasaki, K. Hujita, Y. Hikita, W. Yamamoto, N. Kuriyama, R. Kita, N. Shinyashiki and S. Yagihara, Proc. School Sci. Tokai Univ, 47, 89 - 101, (2012)

7 K. Sasaki, A. Panagopoulou, M. Miyara, K. Fujita, W. Yamamoto, P. Pissis, A. Kyritsis, R. Kita, N. Shinyashiki, and S. Yagihara, AIP Conf. Proc. (in press).

${ }^{8}$ K. S. Cole and R. H. Cole, J. Chem. Phys., 9, $341-$ 351, (1941).

9 R. Buchner, J. Barthel and J. Stauber, Chem. Phys. Lett., 306, 57 - 63, (1999). 